\title{
Academic Institutions Are No Different to Any Other: Total Quality Management Does Enhance Performance
}

\author{
Elham S. Hasham
}

Notre Dame University Lebanon

\begin{abstract}
Keywords:

Organizational Behavior, Quality Management,

Higher Education,

Corporate Culture,

Enhanced Performance

Received

17 May 2018

Received in revised form

22 September 2018

Accepted

There are many skeptics about the contributions of Total Quality Management (TQM) to education because of its roots in the world of business. TQM says nothing about actual production but stresses the process of management and collaboration within the system to reach quality output. Any quality-conscious organization, despite the nature, should understand this. This paper will not present any innovative ideas but will define TQM and focus on its influence on the various facets of an institution of higher education. TQM helps to provide better services to its primary customers-students and the community. Moreover, TQM focuses on continuous improvement and growth that can offer an enhanced and challenging learning environment for all involved. Thus, a more effective and efficient corporate culture emerges.
\end{abstract}

30 September 2018

Correspondence:

hashamelham@gmail.com

Total Quality Management (TQM) is a style of management that has been receiving growing attention for decades. The vision of TQM promises unity, teamwork, autonomy and empowerment. The phrase total quality comes from 'total quality control' originally coined by Feigenbaum (1993). Quality is whatever the customer wants it to be. The customer's needs, wants and expectations must be identified. The goal, hence, will be to satisfy the customer by following an effective and efficient strategy. The core values of TQM focus on customers, 
continuous improvement, top management commitment, system and process control, employee involvement, and managerial decisions based on facts (Svensson \& Klefsjo, 2000).

The five pillars (Creech, 1994) as a foundation of TQM have been listed as Product, Process, Leadership, Organization and Commitment. They are interdependent and if one is weak, the others are influenced. The framework for a quality process (Crosby, 1979) focuses on the mission, customers, a systematic approach to operations; leadership; vigorous development of human resources; and long-term thinking.

Building a quality organization takes a shared commitment, a common language and a workable blueprint (Butler, 1998). TQM is not a passive description term but an energetic activity (Sherr \& Lozier, 1999). Atkinson (1990) says that TQM is an organization-wide commitment to getting things right. Since TQM affects everyone in the organization, everyone without resistance must accept it. TQM is 'an approach to improving the effectiveness and flexibility of business as a whole' (Oakland, 1989).

Deming (1993) is widely recognized as the 'father' of the TQM movement. He did most of his effective teachings behind the scenes in Japan. Deming presented his fourteen points that basically stress on the constancy of purpose toward the overall improvement of quality in everything that an organization does. A critical step in TQM implementation is customer identification, in addition to leadership, cultural and organizational issues. While higher education institutions do house learning and create knowledge, they still encounter challenges in embracing TQM. Research (Bennett, 2001; Grant, 2002; Lyness \& Heilman, 2006; Ruben, 1995; Tranter, 2001) show that quality in higher education is treated from various perspectives because the needs of the 'customer'-the student are pertinent to the market needs and requirements.

TQM requires the development and application of education and training programs for effective business management, knowledge and practices of specific tools and techniques that ensure continuous business improvements (James, 1996). To illustrate continuous improvement, Deming (1982) uses the Shewhart Cycle identified as the PLAN, DO, STUDY, ACT cycle which is a continuum of the process; it is on-going; it is never-ending; it is quality. Deming (1993) also became familiar with 'The Three Cs'. These constitute a focus on Customers, Culture and Capacity to develop an organic and integrated set of relationships, gain the ability to change and direct those relationships in the course of improvement as defined by the organization's internal and external customers.

Moreover, the philosophy of TQM involves a complete and comprehensive integration of the business resources to acquire effectiveness and efficiency. Customer fulfillment should thus, be unified with the organization's business plan and corporate strategy. In other words, the ideology of TQM requires total commitment and involves everything and everybody (Fallahnejad \& Lori, 2015). That is, the overall objective of TQM is to avoid shortcomings and to get it right, the first time, and every time. One of the most powerful bankers of his era, J. P. Morgan (1837-1913) stated, "the goal is to do first-class business in a first-class way." The latter is applicable to all organizations no matter what the nature or industry is.

Furthermore, as TQM focuses on quality services from top management to lower level employees, the organization enhances customer satisfaction and loyalty, minimizes expenses and fosters esprit de corps and teamwork. The stress is on 'prevention rather than inspection'. 
Accordingly, employees feel more committed when management shows them that they are an integral part of the whole process and that they are trusted. As a result, empowered employees feel more involved and are encouraged to make quality decisions for the betterment of the organization. Marvin Bower (1903-2003), founder of McKinsey \& Company in 1939 and considered to be the 'father of modern management consulting' stated it so eloquently, "a successful organization usually consists of a group of talented people who like and respect one another. The firm nurtures in its people the ambition and the determination to be outstanding at what they do. The firm encourages intellectual disagreement and interaction among its members but insists upon mutual respect. The firm tries to enable outstanding people to flourish by leveraging their skills and providing a creative environment. It never permits any relaxation of professionalism or of high standard."

In general, TQM is not just about management but a complete change in an organization's culture and the behavior of people at work. One relevant and interesting definition (Oakland, 1999) of TQM is "An approach to improving the effectiveness and flexibility of business as a whole. It is essentially a way of organizing and involving the whole organization; every department, every activity, every single person at every level. For an organization to be truly effective, each part of it must work properly together, recognizing that every person and every activity affects and in turn is affected by others."

\section{The Relationship between TQM and Leadership}

A significant definition of leadership: ... is a broad visionary activity that seeks to discern the distinctive competence and values of an organization; to articulate and exemplify that competence and those values; to inspire, even to transform people in the organization to feel, believe and act accordingly (Mukhi, Hampton, \& Barnwell, 1988).

Leaders are individuals who influence people positively and secure the objectives set by the organization. As a result, leadership is not an individual orientation, but a group one and therefore, involves other people. By providing an appropriate and comfortable environment, leaders offer group members the means of motivation for goal or task accomplishment (McGregor, 2006; Risher, 2005). David Ogilvy (1911-1999) who was considered the 'father of advertising' viewed the leader's principal role as "providing an environment in which creative people can do useful work."

In addition, Max Dupree (1924-2017) fostered the notion of an inclusive corporation-one where all voices are heard and open communication dominates. For Dupree, a caring organization was synonymous with business success. "Give others the space to be what they can be; if they approach their individual potential, so will the organization." Yet another guru, Warren Bennis (1925-2014) was the 'pioneer of the contemporary field of leadership studies' and he highlighted that humanistic and democratic leaders are better suited for effectiveness and efficiency. Bennis stressed that what is pivotal for the leader is "to have an overreaching vision, to set an example of passion, curiosity, integrity, and daring for the others in the organization."

In view of the above mentioned authorities, we cannot overlook the insights of Peter Drucker (1909-2005), an expert who invented the concept of Management by Objectives (MBO) and considered the 'founder of modern management'. Drucker said, "a business is not 
defined by the company's name, statutes, or articles of incorporation. It is defined by what the customer satisfies when he buys a product or service. To satisfy the customer is the mission and purpose of every business. The customer only wants to know what the product or service will do for him tomorrow. For this reason alone, any serious attempt to answer, "what our business is' must start with the customer, his realities, his situation, his behavior, his expectations, and his values."

To ensure that the ultimate client is continuously satisfied, TQM requires increased effort from everyone in the organization. It means nothing if shared power, responsibility and commitment of staff and management move in opposite directions. Strategic quality leadership means developing everyone as leaders. This can be achieved through motivation by the delegation of authority where implementation of the plan is based on trust and confidence. The process is monitored and feedback is analyzed. Leaders then can exercise their power in accordance to performance and outcome by generating an atmosphere in which employees are aligned with management in achieving the organization's objectives. Realizing success in quality management is contingent on $10 \%$ of technical equipment, $40 \%$ of technology and $50 \%$ on people and style of management (Hamrol, 2005).

In the previous section, the researcher underlined the works of W. Edwards Deming (1982; 1993) as he defined total quality management. In this section, let's highlight a few leadership behavioral traits that Deming (1993) suggests are crucial for quality output:

1. Understands to what extent group work corresponds to the company's objectives;

2. Attempts to ensure comfortable working conditions so employees find their job fulfilling;

3. Functions as a coach, and an advisor, but does not judge;

4. Works on system improvements and cooperates with fellow employees;

5. Inspires confidence and enables employees to carry out their tasks;

6 . He is a listener and a learner at the same time.

Moreover, management's task has become one of being a leader in learning (Long, 1993) and the quality-oriented organization is a learning organization. Essentially, management must cultivate a culture of leadership from top management through to all levels in the organization (Staub, 1993), where team-based leadership measures are emphasized (Tompkins, 1993). The objective is to create an organization committed to continuous improvement, or as the Japanese term it, KAIZEN (Mohammed \& Khayum, 2015). Quality improvement is continuous, not only related to the final product but also to everything that the organization does and is involved with. Thus, management must seek employees who are trustworthy, honest, and open to other employees. They must believe in their capabilities, authority, charisma, and professionalism for quality performance (Fotopoulos \& Psomas, 2010).

Any process involves three major phases - Planning, Implementing, and Evaluating. Quality leadership is dependent on quality planning so that the others may be pursued. This revolves around developing the mission, objectives and strategies. Quality-oriented leaders (Meftah \& Gibson, 2013) ensure that their planning processes are effective by securing and emphasizing staff involvement, using resources - physical, human and financial - according to 
the quality plan and effectively implementing them. Research (Ahmad \& Yekta, 2010) has shown that leadership behavior combined with perceived organizational support should lead to job satisfaction, hence employee involvement and finally quality productivity and performance.

To conclude, leaders are essential in creating a quality culture and they play a significant role in assuring that the required resources are available to support quality initiatives. There are many quality principles (Sherr \& Teeter, 1991; Watkins, 2004) that could help leaders to change the culture of higher education institutions and also encourage synergy within the whole system. The quality principles include leadership and creating a quality corporate culture, vision, mission, collaboration, and delegation of decision making.

\section{The Relationship between TQM and HRM}

Human resource management (HRM) is the process of designing workforce measures and activities in order to enhance the efficiency and effectiveness of organizational performance (James, 1996). In this respect, quality and HRM seem to be in tune. The major key to effective quality practices is the management of human resources. Today, the quality-oriented organization is specifically focused internally on effectively uniting systems and human relations, and externally, at ensuring communication to and from suppliers and customers. HRM can enrich interpersonal skills, enhance employee competence and facilitate adaptation. Consequently, HRM is a prerequisite for effective TQM practice (Palo \& Padhi, 2005). In other words, total quality management relies entirely upon active management of human resources (Hoogervorst, Koopman, \& Van der Flier, 2005). Rigorous research (Boselie \& Van der Wiele, 2002) has concentrated on the influences of HRM and TQM on organizational productivity and performance.

In the case of educational institutions, the customers are the students and the suppliers are all administrators, faculty and staff and this issue will be elaborated in the next section. Human Resource Management (HRM) and Total Quality Management (TQM) utilize High Performance Work Practices (HPWP) (Boon Arumgam, Safa, \& Bakar, 2007). These practices include performance appraisal, selective hiring, reward systems, leadership, training, and customer focus that drive companies to excellence. Moreover, a production analogy (Baldridge National Quality Program, 2002) for higher education highlights the following: universitiessuppliers; admitted high school graduates-raw materials; students-product-in-process; coursesprocess stages; graduates-finished product; employers-customers; number of graduates employed-sales; starting salary-price.

The vehicle of Investors in People emerges from Human Resource Management and is linked to managing and achieving organization-wide change by being a mechanism that supports TQM. By investing in people, management makes a public commitment to develop all employees to achieve business objectives (Thackwray \& Hamblin, 1996). Consequently, management communicates a vision of where the organization is going and how employees can contribute to this success. Moreover, the training and development needs of employees are visited to assess achievement and future effectiveness.

Human relations is about organizational processes, leadership style, motivation, satisfaction, and teamwork. Hence, the impact of HRM observation on TQM embraces training, incentive plans, employee development, in addition to recruiting and selection. An evaluation and 
reevaluation of the effectiveness of the practices that affect quality-related activities must be implemented (Tyler, 2004). Such information would be related to management, policies and procedures, individual opportunities, performance characteristics, performance appraisal, reward structure and process improvements. Furthermore, quality-performance characteristics include esprit de corps, problem-solving skills and the ability to develop and apply concepts (James, 1996).

\section{Quality Management in Higher Education}

The need for TQM to be adopted organization-wide is paramount. TQM is an approach to promoting the effectiveness and efficiency and flexibility of business as a whole; it is essentially a way of organizing the whole organization (Oakland, 1989). To do this, TQM must start at the top with the most senior management demonstrating their seriousness toward quality. Open and proper communication channels must be followed with a focus on teamwork. The importance of a positive attitude and commitment cannot be overemphasized. Without them, there will be failure. In accordance, the strict relationship between TQM and HRM has been discussed in the previous sections. At the 4th International Conference on TQM, Cook (1991) highlighted that if TQM is introduced without considering its consequences on people. It can lead to failure if the significance of the role that HRM plays in the overall process is overlooked (Hubiak \& O’Donnell, 1996). TQM encourages quality working attitudes, quality awareness and focuses on guiding towards teamwork, continuous improvement and participation.

Higher Education (HE) is probably one of the most important service sectors in modern business. Quality management in HE refers to the totality of features and characteristics of product services that bear on its ability to satisfy stakeholder expectations (Higher Education Quality Council, 1996). "Supplier's activities at the interface with a customer, and the results of all supplier's activities to meet customer needs" (International Organization for Standardization, 1992). Service-oriented organizations operate through a distributed delivery network and require a standardized approach for management and customer satisfaction. The quality movement has spread widely across service institutions such as banking, insurance, non-profit organizations, healthcare, government and educational institutions. No matter what type of institution, they all require teamwork, top management leadership, customer focus, employee involvement, continuous improvement tools, and training (Murad \& Rajesh, 2010).

Education is our business. Could it be more crucial to implement quality than in an educational institution? Our clients are our students whom we must serve with the best we have to offer. All levels of the organizational structure are involved. President, Vice-president, Provost, Deans, Directors, Chairpersons, Advisors, Faculty and Staff are all participators in the quest for quality performance. Collaboration among all players will result in effectiveness (doing the right thing) and efficiency (doing things right). If institutions of higher education want to implement TQM to enhance productivity, participative management is to be contemplated. With a clear mission determined by objectives/goals, a well-structured strategy, distinct job descriptions, open communication, allocation of resources for implementation and top-management support, performance will be enhanced. The consequence will be quality productivity from one echelon to the other. 
Bryan (1996) describes TQM implementation in the HE context as: "...a comprehensive philosophy of operation in which HE institutions community members (1) are committed to continuous quality improvement, and to a common campus vision, set of quality values, attitudes, and principles; (2) understand that campus processes need constant review to improve services to customers; (3) believe that the work of community members is vital to customer satisfaction, and (4) value input from customers for further improvement."

Many skeptics (Simmons, 2003; Smither, London, \& Reilly, 2005) find that TQM is just the 'latest jargon' for collaboration and participative management. No matter what terminology it is given, the common principles and philosophies of the renowned quality management gurusDeming, Juran, Crosby, Garvin, Taguchi - are at the core of the movement. Despite the controversy, the quality movement is making its way into the arena of higher education because the concept of TQM as a possible remedy for their ills is being acknowledged.

Why is quality performance so important in educational institutions? By nature, educational institutions are in the business of education and change. Since TQM requires a high investment in education and training, the educational institution seems to be the perfect place to implement the concept. However, it is not as easy as it sounds. Individuals in educational institutions question and debate the philosophy of TQM and its challenges to the accepted management theory (Saunders \& Walker, 1991). The rationale is that TQM creates problems of bureaucracy that are seen as detrimental to the 'effective' operation of the working teams or groups.

Without a doubt, TQM can definitely assist the management in education by offering the customer-oriented concept where customers can be both internal and external (Cornesky, Clark, \& Emerson, 1992). The domains that differentiate the education from the manufacturing sector are objectives, processes, inputs and outputs (Tribus, 1994). "Education is different from industry. But managing people and resources is largely the same for any organization, whether in business or education, the private sector or the public arena" (Siu \& Heart, 1992).

Moreover, education has its own set of values and practices with specific focus and objectives. These concerns could be overlooked if the educational institution is managed in a total quality way. Therefore, just like any other organization, educational institutions, especially those of higher education, need to learn how to learn about quality and its implications in order to survive and grow. Consequently, quality issues also need to focus on internal politics as well as to determine effective quality measures that can empirically demonstrate improvement in process deliberations (James, 1996).

Furthermore, the justification for implementing TQM in the HE institution depends on the specific internal and external conditions that act as a basis of strategic planning related to TQM. The ability to establish suitable measures of performance is a key element for TQM success (Brigham, 1993). It is not easy to measure services; however, close interaction and continuous attention to customer satisfaction can determine a positive check point.

In higher education, there is a stark realization that poor quality causes waste. In addition, a distinction must be attained to improve profile or arrest any possible decline. Universities operate in an 'unstable and confusing environment' which has seen the loss of the sedate style of traditional university management (Duke, 1992). Universities cater for their students - their customers - and such customers demand quality. The only way to supply such quality is to start at the top of the pyramid and secure each link in the chain so that the final product will be up to 
standard. For instance, students could withhold their fees to a university because they are dissatisfied with the changes made to their courses (Bulpitt, 1995).

In sum, academicians hesitate to use the term customer to describe students because they believe that it signals their acceptance of the cliché 'the customer is always right' (Wolverton, 1993). TQM doesn't suggest that students hold sole proprietorship over content determination but that they are involved as active and creative participants in the education process. Quality education then results from a multi-faceted effort on the part of all involved. Suffice to say that such a quality movement fosters innovation, creativity, personal initiative and risk-taking.

\section{Does TQM Enhance Performance in Academic Institutions?}

The President of Babson College, William F. Glavin, believes that TQM for academic institutions is a necessity and not a luxury. He says that our customers (students and those who pay tuition bills) must be kept satisfied by meeting their requirements. At Babson, quality has become the foundation for its future culture. The Office of Quality educated over 30\% of all staff employees during 1993. They are committed to meeting customer requirements. For example, the graduate admissions office staff decided to seek ways to improve the enrollment process. They discovered that eight mailings were being sent to accepted students and they used the 7-step problem-solving process to combine these mailings into one package, which eliminated 220 staff hours of waste time.

Similarly, The University of Pennsylvania reduced trash removal costs and streamlined research cost recovery procedures. The University of Kansas reduced the time spent to generate a student work-study check from sixteen days to three. The Universities of Miami and Chicago have integrated TQM into their MBA curricula and into classroom and support service functions that have led to student (customer) satisfaction (Cornesky et al., 1992). In 1989, Oregan State University brought in speakers and consultants, including W. Edwards Deming and staged retreats designed to educate colleagues and to build support. In 1990, TQM went institution-wide and among the changes were reduced remodeling job time by $23 \%$ and department journal voucher errors decreased by $94 \%$ (Coate, 1990).

For successful implementation of TQM in universities, a complete alignment of all staff is required (Todorut, 2013). The quality culture of the institution has an outstanding effect on the actual application. That is, the institutional culture should integrate the values, beliefs, norms into behavioral patterns of faculty and staff to provide a quality learning experience for students. For example, the prominent Oxford, Cambridge and Harvard universities are celebrated not only for their academic excellence but also for their unique institutional cultures. As a result, their graduates are preferred and looked upon with high esteem. In higher education, it is crucial to constantly improve quality for TQM is an ongoing process. Consequently, the TQM pyramid in higher education starts with quality on the marketplace in the upper echelon; the quality of its own work-the politics of the university-the quality of collaboration in the middle echelon; and the quality of educational services in higher education at the lower echelon (Vinni, 2011).

From 2000-2006, the researcher was Director of Admissions and International Recruitment at Notre Dame University (NDU) in Lebanon (www.ndu.edu.lb) and a great advocate of TQM. The staff members of the office were entrusted to implement procedures. Flaws were discussed 
and suggestions for improvement were made based on individual cases. Engaging staff in quality circles was extremely rewarding with a translation into a high level of commitment. Communication was open with staff participating in the decision-making process and this instilled satisfaction and displayed enthusiasm. They were also given the opportunity to take personal initiative and thus, entrusted to take quality action. There was stress on teamwork and job rotation where all members of the office assisted one another and got involved. The 'WE' and not the 'I' was the dominant culture and this enhanced loyalty and commitment to NDU.

NDU took the strategic decision to adopt the concept of TQM during the academic year 2000-2001 and ever since it has been witnessing reengineering in administration, academic programs and structure. Consequently, policies and procedures and by-laws have been rewritten with the objective of reaching the maximum potential of all involved for the quality improvement of the institution. There have been a number of task forces and ad-hoc committees appointed to identify problems, offer alternatives, analyze the options, and choose the solution that is found to be the best for the enhancement of the respective process. One significant course of action has been the revolutionary revision of the curricula to meet the graduation requirements of our 'customers'.

In addition, task forces have been appointed to not only suggest more effectiveness and efficiency with all operations but also facilitate activities institution wide in addition to allowing students smoother procedures. Technological advancements have been introduced with the implementation of an E-Learning center and the use of Blackboard. Registration can be finalized on-line. The accreditation process has been launched. The strategy, mission and goals are being revisited and developed. Furthermore, institution wide surveys have been conducted to review job descriptions and ranking scales. The overall objective is to keep human resources satisfied and motivated to perform in the most effective and efficient way possible and thus, be more productive.

In accordance to Bryan's definition (1996) of implementing TQM in HE, NDU does practice its core values. Continuous quality improvement is enhanced through regular training sessions such as employee performance appraisals and these are based on needs analysis. The common campus vision is stressed through the strategy of NDU and deep and profound interpretation sessions related to the mission statement. Moreover, the mission statement is clearly mentioned in our syllabi to ensure that students also are aware. The KSAs-knowledge, skills, attitudes- of all people at NDU are identified to encourage self-development. A constant review of curricula and all services contributes to quality improvements and amendments. Organization wide the stress is on the satisfaction of our students and the community at large. Furthermore, constant evaluations and feedback have contributed to any changes, amendments and improvements.

Consequently, the researcher can affirm the following strides that Notre Dame University (NDU) has taken to meet customer and market needs and to offer quality services in a very competitive environment. The most noteworthy step was the application for institution wide accreditation from NEASC-New England Association of Schools and Colleges, Inc. NDU was granted candidature after a profound self-study was submitted and the final visit of the NEASC board to NDU is in April, 2018. In 2016, the undergraduate degree of the Faculty of Engineering was officially and fully accredited by the Engineering Accreditation Commission 
of ABET-the global accreditor of college and university programs in applied science, computing, engineering, and engineering technology.

By the same token, the Faculty of Business Administration \& Economics has been declared eligible for accreditation by the Association to Advance Collegiate Schools of Business (AACSB) and is currently writing its self-study. The Department of Media Studies has applied for accreditation from the International Association of Film and Television Schools (CILECT). In sum, every department of each faculty is continuously revamping its programs to meet the ever changing needs of the student based on those of the marketplace.

Among the various other measures that NDU has taken for quality development are the establishment of an Office of Mission and Vision that is concerned with revisiting the mission statement and making necessary adjustments to meet student requirements. Additionally, the overall strategy and by-laws are being revised and updated. NDU is also a member of the most prominent international associations and committees and has signed numerous MOUs with major institutions of higher education from all over the world.

Thus, and to be more specific, the guiding principles that are deliberated in any business industry are the same to be considered in education. A thorough awareness of the market needs and competition are also fundamental in academia. Universities, too, must stay abreast the turbulent environment we are exposed to. The confidence of students, parents and the society is enhanced when they see their institution aiming to develop itself through evident constructive change and especially when accreditation is initiated (Stanciu, 2003).

\section{Conclusion}

In the 21 st Century, it is crucial that organizations, especially those of higher education embrace Total Quality Management as a means of improvement by ensuring that all stakeholders comprehend the complexity, challenge and functional interrelationships of a TQM system. Exposure to TQM appears to be growing, still many consider it the latest 'fad' and agree that it will not become a lasting legacy. In reply to this, one TQM guru, Philip Crosby (1995) assets that T (Total) QM may be an illusion that will pass, like other management fads; however, Quality Management (QM) will never die. It provides the basis for grasping opportunities, enhancing organizational strengths and reducing the effects of weaknesses and threats.

Moreover, TQM is not a panacea for the ills of today's business course. Nonetheless, it can be seen as structured, yet a flexible approach; cohesive, yet a loose amalgamation of methodologies and applications; constructive, yet it breaks down barriers; understandable, yet complex; changing, yet standardized; stable, yet dynamic; co-operative, yet independent (James, 1996). The key to future strength is to perceive TQM wholeheartedly and re-engineer all processes in an organization so that they operate as integrated units. Managers and workers must collaborate as partners in the innovative quality revolution as the speed and complexity of change continues to accelerate.

Furthermore, the decision for a university to adopt TQM must be studied carefully. Quality system failure in higher education (Crawford \& Shutler, 1999) identifies the root causes as weak students (poor input); lack of focus in teaching (poor delivery services); lack of attention paid to performance standards and measurement; unmotivated staff (internal customer 
satisfaction); neglect of students' skills (quality potential). There may be either minimal commitment or total rejection of the whole concept. To avoid such mishaps, five common conditions must be met (Wolverton, 1993):

1. Strong visionary leadership and top management commitment.

2. A sufficient base of support for change to manifest itself.

3. The costs of training, educating and reeducating must be recognized.

4. Acknowledgement of the problem and have the proper resources and enough time to solve it.

5. Faults must not be confined only to administration; everyone must be willing to accept the change.

In conclusion, no matter what country, what type of organization or even what kind of project, TQM will succeed only if customer/supplier needs and expectations are recognized. Quality, with capital Q, is the key to business growth and success. Processes and improvements must be managed with a policy that provides motivation through quality leadership. The culture must change and empower people. Communication will formulate a network that will eliminate barriers and fear. Commitment will be displayed through on-going education and training and a clear strategy.

In summary, this paper has revealed the basic principles of TQM emphasize customer orientation, employee involvement, and continuous improvement, strategic approaches to improvement, integrated systems, decision making, and open communication. Overall, organizations and institutions of higher education should aim to be the best they can be by concentrating on customers, recruiting and retaining talented people and creating a corporate culture that will stimulate creativity. A clear vision, comprehensible business philosophy and flexibility will pave the road to excellence.

\section{Recommendations}

Institutions of higher education will undergo educational reform through synergy, continuous improvement, a system of ongoing process and the support and leadership of top management. Everyone in the institution must believe and understand the TQM principles by redefining the role, purpose and responsibilities; planning comprehensive leadership training at all levels; and creating staff development to address attitudes and beliefs.

To display a total commitment to quality management, all members of the institution must exercise extreme commitment to the organization strategy and mission; identify the resources needed to meet training and development; cooperate with top management for effective and efficient output; be encouraged to meet job-related needs; be actively involved in synergy; understand the importance of communication to the process.

Inevitably, TQM is an imperative element in modeling the strategies of institutions of higher education so they can fully satisfy their stakeholders-students, parents, society, market place. This calls for innovation, flexibility and allowing employees to reach their full potential which, in turn, will increase self-esteem and motivate individuals to show quality performance. The synergy among the factors outlining TQM results in outstanding improvements in performance. In addition, a great stress must be made on training as a tool to improve employee performance, operational performance and hence reaching customer satisfaction. 
Thus, to obtain the most potential from the Total Quality Management philosophy in the future, 'the new pillars of TQM' (James, 1996) should be developed as a single integrated system. Consideration should be given to establishing a quality corporate culture, process and structure; to staying abreast of the contemporary technological developments; to the academically professional allocation of physical, financial and human resources; and to the satisfaction of both internal and external 'customers'.

\section{References}

Ahmad, Z. A., \& Yekta, Z. A. (2010). Relationship between perceived organizational support, leadership behavior, and job satisfaction: An empirical study in Iran. Intangible Capital, 6(2), 162-184.

Atkinson, P. E. (1990). Creating culture change: the key to successful total quality management. San Francisco: Pfeiffer.

Baldrige National Quality Program (BNQP). (2002). Education Criteria for Performance Excellence. Baldrige National Quality Program, National Institute of Standards and Technology.

Bennett, D. C. (2001). Assessing quality in higher education. Liberal Education, 87(20), 40-46.

Boon, O. K., Arumgam, V., Safa, M. S., \& Bakar, N. A. (2007). HRM and TQM: Association with job involvement. Personnel Review, 36(6), 939-962.

Boselie, P., \& Van der Wiele, T. (2002). Employee perceptions of HRM and TQM and the effects on satisfaction and intention to leave. Managing Service Quality: An International Journal, 12(3), 165-172.

Brigham, S. (1993). TQM lessons we can learn from industry. Change, 42-48.

Bryan, W. A. (1996). What is quality management? New Directions for Student Services, 76, 3-15.

Bulpitt, G. (1995). Student charters. Paper presented at the Bournemouth University Library and Information Services Conference, Bournemouth, Dorset, England

Butler, D. (1998). Introduction and overview of the David Butler TQM process. Ohio: David Butler Associates, Inc.

Coate, L. E. (1990). Implementing TQM in a university setting. Oregan: State University.

Cook, B. (1991). Total quality management research. Proceedings of the $4^{\text {th }}$ International Conference of Total Quality Management, IFS Publications.

Cornesky, R. A., Clark, J. M., \& Emerson, R. W. (1992). Using Deming to improve quality in colleges and Universities. Madison, PA: Magna Publications.

Crawford, L. E. D., \& Shutler, P. (1999). Total quality management in education: problems and issues for the classroom teacher. The International Journal of Educational Management, 13(2), 67-72.

Creech, B. (1994). The five pillars of TQM. New York: Truman Talley Books.

Crosby, P. B. (1979). Quality is free. New York: McGraw-Hill.

Crosby, P.B. (1995). Quality time (letter). The Economist. February, 4(6).

Deming, W. E. (1982). Quality, productivity and competitive position. Cambridge, MA: Massachusetts Institute of Technology. Center for advanced engineering study.

Deming, W. E. (1993). Leading quality transformations. Executive Excellence, 10(5), 4-4.

Duke, C. (1992). The learning university: Toward a new paradigm. The Cutting Edge Series. Bristol: Taylor and Francis.

Fallahnejad, M., \& Lori, E. S. (2015). A framework for connection between total quality management and innovation processes. Cumhuriyet Science Journal, 36(3), 1515-1524.

Feigenbaum, A. V. (1993). Feigenbaum's window on the world: Regaining the quality service edge. National Productivity Review, 12(4), 457-461.

Fotopoulos, C. V., \& Psomas, E. L. (2010). The structural relationships between TQM factors and organizational performance. The TQM Journal, 22, 539-552.

Grant, D. M. (2002). Measuring the dimensions of quality in higher education. Total Quality Management, 13(1), $123-132$.

Hamrol, A. (2005). Zarzadzanie jakoscia z przykladami [Quality Management in Examples]. Wydawnictwo Naukowe PWN, Warszawa.

Higher Education Quality Council (HEQC). (1996). Guidelines on quality assurance. London: HEQC. 
Hoogervorst, J. A. P., Koopman, P. L., \& Van der Flier, H. (2005). Total quality management: The need for an employeecentered, coherent approach. The TQM Magazine, 17(1), 92-106.

Hubiak, W. A, \& O’Donnell, C. (1996). Do Americans have their mind set against TQM? National Productivity Review, 75(3), $19-32$.

International Organization for Standardization (ISO). (1992). ISO 9000 International Standards for Quality Management. (2 ${ }^{\text {nd }}$ ed.). Geneva: ISO.

James, P. T. J. (1996). Total quality management: an introductory text. USA: Prentice Hall.

Long, D. (1993). Changing role of corporate planning. Executive Excellence, 10(6).

Lyness, K., \& Heilman, M. (2006). When fit is fundamental: Performance evaluations and promotions of upper level female and male managers. Journal of Applied Psychology, 91(4), 777-785.

McGregor, J. (2006). The struggle to measure performance and reliability management. Business Week, 30, 920-941.

Meftah, A. F. \& Gibson, P. (2013). Experiences of TQM elements on organizational performance and future opportunities for a developing country. International Journal of Quality.

Mohammed, H., \& Khayum, O. (2015). Kaizen: Potentiality in utilization of human prospects to achieve continuous improvements in the quality of higher education. International Journal of Multidisciplinary and Current Research, 3, 12231229.

Mukhi, S., Hampton, D., \& Barnwell, N. (1988). Australian Management. Sydney: McGraw-Hill.

Murad, A., \& Rajesh, K. (2010). Implementation of total quality management in higher education. Asian Journal of Business Management, 2(1), 9-16.

Oakland, J. S. (1989). Total quality management. Oxford: Butterworth Heinemann.

Oakland, J. S. (1999). Total organizational excellence: Achieving world-class performance. Oxford: Butterworth-Heinemann.

Palo, S., \& Padhi, N. (2005). How HR professionals drive TQM: A case study in an Indian organization. The TQM Magazine, 17(5), 467-485.

Risher, H. (2005). Getting serious about performance management. Compensation and Benefits Review, 18-26.

Ruben, B. D. (1995). Quality in higher education. New Brunswick, N. J: Transaction Publishers.

Saunders, W., \& Walker, M. (1991). TQM in tertiary education. International Journal of Quality and Reliability Management, $8(5), 91-102$.

Sherr, L. A., \& Lozier, G. G. (1999). Total quality management in higher education. The University of Kansas: Pennsylvania State University.

Sherr, L. A., \& Teeter, D. J. (1991). Total quality management in higher education. New Directions for Higher Education. San Francisco: Jossey-Bass.

Simmons, A. (2003). When performance reviews fail. Training and Development, 57(9), 47-53.

Siu, R. Y., \& Heart, S. J. (1992). Management manifesto. The Executive Educator, 14(1), 23-26.

Smither, J. W., London, M., \& Reilly, R. R. (2005). Does performance improve following multi-score feedback? A theoretical model, meta analysis, and review of empirical findings. Personnel Psychology, 58, 33-36.

Stanciu, I. (2003). Total quality management. Editura Cartea Universitara, Bucharest, 301-324.

Staub, D. (1993). A culture of leadership. Executive Excellence, 10(2).

Svensson, M., \& Klefsjo, B. (2000). Experiences from creating a quality culture for continuous improvements in Swedish School sector by using self-assessments. Total Quality Management, 11(4,6), 800-807.

Thackwray, B., \& Hamblin, H. (1996). Total quality management, investors in people and higher education. Engineering Science and Education Journal, 113-119.

Todorut, A. V. (2013). The need of total quality management in higher education. Procedia-Social and Behavioral Sciences, $83,1105-1110$.

Tompkins, J. A. (1993). Term-based continuous improvement: How to make the pace of change work for you and your company (Part 1). Materials Handling Engineering, 48(2), 59-63.

Tranter, P. (2001). Measuring quality in higher education: A competency approach. Quality in Higher Education, 7(3),191198.

Tribus, M. (1994). TQM in education: The theory and how to put it to work. In quality goes to school: Readings on quality management in education. American Association of School Administrators, 37-40. 
Tyler, K. (2004). One bad apple: Before the whole bunch spoils, train managers to deal with poor performance. HR Magazine, $49(12), 77-86$.

Vinni, R. (2011). Total quality management and paradigms of public administration. International Public Review, 8(1), 15-23.

Watkins, T. (2004). Have a heart. New Zealand Management, 51(2), 46-48.

Wolverton, M. (1993). TQM in higher education: Latest fad or lasting legacy? Policy briefs of the education policy studies laboratory. Arizona State University, 3, 1-14. 